\title{
BOTTAPOTAMON NANAN, A NEW SPECIES OF FRESHWATER CRAB (DECAPODA, BRACHYURA, POTAMIDAE) FROM FUJIAN PROVINCE, CHINA
}

\author{
BY
}

\author{
XIANMIN ZHOU ${ }^{1,3}$ ), CHUNCHAO ZHU ${ }^{1}$ ) and TOHRU NARUSE ${ }^{2}$ ) \\ ${ }^{1}$ ) Department of Parasitology, Medical College of Nanchang University, BaYi Avenue 461\#, \\ Nanchang City, Jiangxi Province 330006, People's Republic of China \\ ${ }^{2}$ ) Raffles Museum of Biodiversity Research, Department of Biological Sciences, National \\ University of Singapore, 14 Science Drive 4, Singapore 117543, Republic of Singapore
}

\begin{abstract}
The present study describes a new species of Bottapotamon Türkay \& Dai, 1997 from Fujian Province, China. The new species is compared with similar congeners, differing primarily in the form of the male first gonopod. This study brings the number of known species of Bottapotamon to five.
\end{abstract}

\section{ZUSAMMENFASSUNG}

Eine neue Art der Gattung Bottapotamon Türkay \& Dai, 1997 wird aus der Fujian Provinz in China beschrieben. Ein Vergleich der neuen Art mit ähnlichen anderen Arten der Gattung ergibt hauptsächlich Unterschiede im Bau der ersten männlichen Gonopoden. Die Zahl der bekannten Arten der Gattung Bottapotamon erhöht sich durch die hier vorgelegte Neubeschreibung auf fünf.

\section{INTRODUCTION}

The freshwater crabs of China are very diverse and widely distributed, with Dai (1999) documenting more than 200 species from the country (see also Yeo et al., 2008). Despite the large number of described species from China, new taxa are still being described very frequently (Chen et al., 2003; Naruse et al., 2008). Currently, the genus Bottapotamon Türkay \& Dai, 1997 is represented by only four species from southeastern China, viz., B. engelhardti (Bott, 1967) and B. yonganense (Cheng, Lin \& Luo, 1993) from Fujian Province; B. fukienense

\footnotetext{
3 ) Corresponding author; e-mail: zhouxmjxmu@126.com

(C) Koninklijke Brill NV, Leiden, 2008

Crustaceana 81 (11): 1389-1396

Also available online: www.brill.nl/cr 
(Dai, Chen, Song, Fan, Lin \& Zeng, 1979) from Fujian, Zhejiang, and Jiangxi provinces; and B. lingchuanense Türkay \& Dai, 1997 from Guangxi Province (Dai, 1999; Ng et al., 2008). The genus was established to accommodate species that were previously assigned to Parapotamon De Man, 1907 and Malayopotamon Bott, 1968. The key diagnostic characters are the presence of a short longitudinal suture between male thoracic sternites 7 and 8 , a relatively long distal segment of the male first gonopod, a mesially placed groove on the male first gonopod for the male second gonopod, and an inwardly-directed female vulva. Among the recent, extensive collections of freshwater crabs from Fujian Province, we obtained a new species of Bottapotamon, here named as B. nanan n. sp.

Specimens examined are deposited in the Department of Parasitology, the Medical College of Nanchang Unversity (NCU MCP), China; the Zoological Reference Collection, Raffles Museum of Biodiversity Research, National University of Singapore (ZRC); and National Institute for Parasitic Diseases, Chinese Center for Disease Control and Preventation (CDC-NIPD). Measurements provided are of the carapace length (CL) by the carapace width (CW). The abbreviations $\mathrm{G} 1$ and $\mathrm{G} 2$ are used for the male first and second gonopods, respectively.

\section{TAXONOMY}

Bottapotamon nanan n. sp. (figs. 1, 2)

Material examined. - Male holotype, $22.4 \times 27.2 \mathrm{~mm}$, NCU-MCP 2008.0010, Dongtian County (ca. $24^{\circ} 54^{\prime} 46.95^{\prime \prime} \mathrm{N} 118^{\circ} 16^{\prime} 34.40^{\prime \prime} \mathrm{E}$ ), Nanan City, Fujian Province, coll. Liangsi Chen \& Xianmin Zhou, 13 Aug. 2006. Paratypes, 1 male, $13.0 \times 15.8 \mathrm{~mm}$, CDC-NIPD 2008.0011-1, data same as holotype; 1 female, $13.0 \times 16.4 \mathrm{~mm}$, NCU MCP 2008.0011, data same as holotype; 1 male, $15.8 \times$ $20.1 \mathrm{~mm}, 1$ female, $21.3 \times 26.7 \mathrm{~mm}$, ZRC 2008.0029, data same as holotype.

Description. - Carapace (fig. 1a) broader than long, widest across middle of anterolateral margins, $\mathrm{CW} 1.24-1.27$ times $\mathrm{CL}$ (mean $=1.25, n=3$ ); dorsal surface almost flat, glabrous; epigastric and postorbital cristae low, oblique to frontal margin; cervical groove indistinct, $\mathrm{H}$-shaped gastric groove distinct. Front directed antero-ventrally, anterior margin straight. Supra- and infraorbital margins (fig. 1c) cristate, lined with low granules, suborbital and pterygostomial regions smooth. External orbital angle broad, directed anteriorly inwards, outer margin about 2 times as long as inner margin; epibranchital tooth low but distinct, anterolateral margin convex, lined with rounded granules; epibranchial regions with short rows of granules.

Antennular fossa narrow, oblong. Epistome with posterior margin cristate, lined with uniform granules. Third maxilliped (fig. 1b) rectangular, midlength of merus about half of ischium, exopod reaching proximal quarter of outer margin of merus, flagellum half width of merus. 


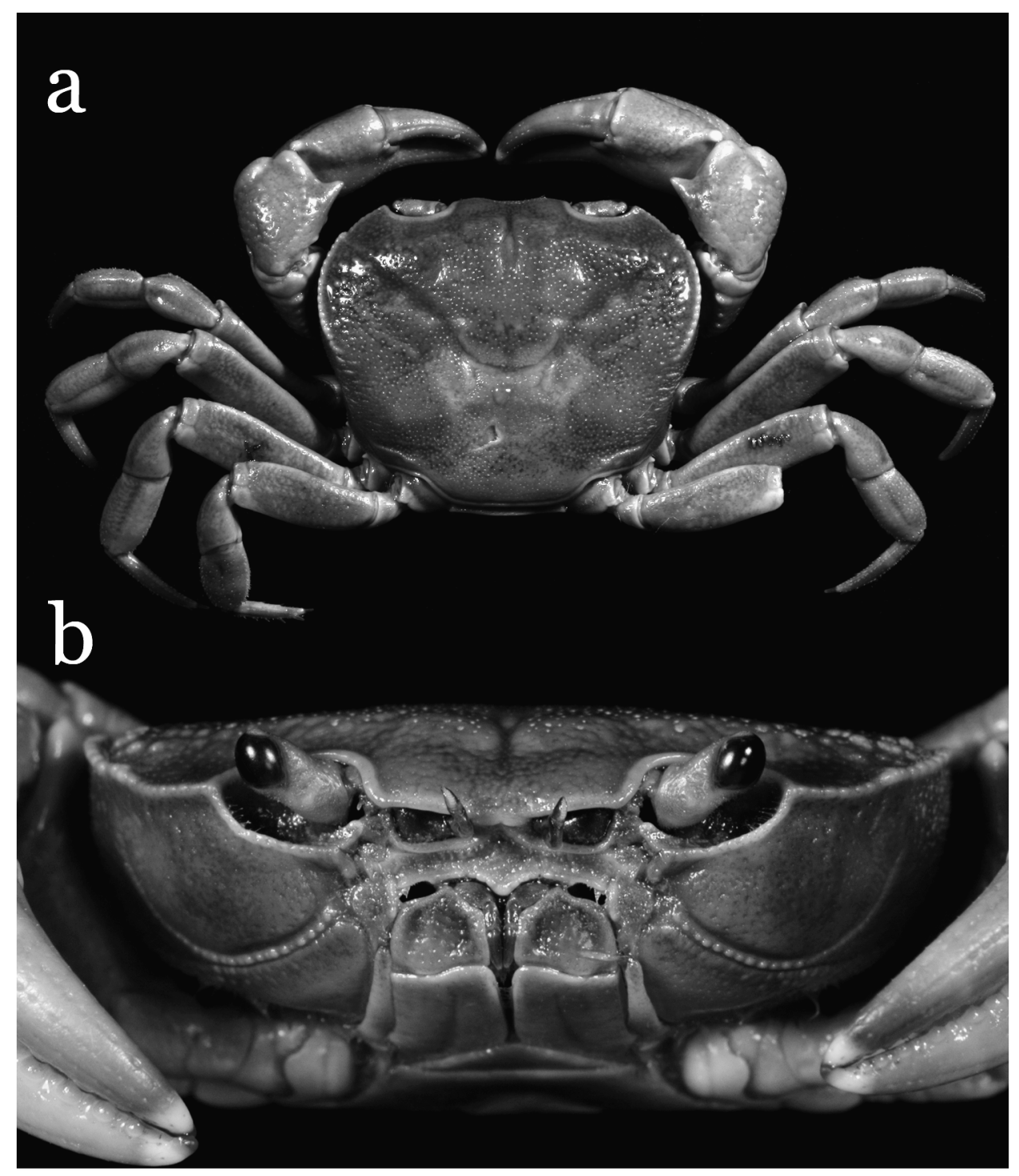

Fig. 1. Bottapotamon nanan n. sp. (holotype male, $22.4 \times 27.2 \mathrm{~mm}$ ); a, habitus, dorsal view; $\mathrm{b}$, cephalothorax, anterior view.

Male thoracic sternites 2 and 3 (fig. 1b) demarcated by transverse shallow groove; sternites 3 and 4 indiscernible. Abdominal cavity reaching beyond imaginary line joining posterior ends of cheliped coxae, cavity relatively wide, distance between inner ends of sutures between thoracic sternites 4 and 5 about half the length of the distance between the sternal condyles; sternal condyle placed slightly posterior to middle of thoracic sternite 5 . 
Chelipeds subequal in males (fig. 1a, b); merus with granulated dorsal and ventral margins, dorsal granules larger; carpus with strong inner angle, with inwardly-directed granule on proximo-ventral part of base of inner angle; palm (fig. 2b) with moderately convex outer surface, with reticulate pattern; fingers shorter than palm, gape narrow when chela closed, cutting edge lined with low teeth.

Ambulatory legs (figs. 1a, 2b) relatively short, second longest when stretched laterally, combined length of merus to dactylus of second ambulatory leg 1.6-1.7 times CL; anterior margins of meri smooth, without subdistal angle, merus of second ambulatory leg 0.6-0.7 times CL; carpi and propodi relatively short, high; dactyli longer than respective propodi in first to third legs, subequal in fourth leg, dactyli with 4 rows of spines, spines of first to third legs small, spines of fourth leg, especially of outer margins, stronger, subdistal spine of outer dorsal margin stronger than distal spine.

Male first abdominal segment (fig. 2a) with transverse ridge; third segment widest; telson triangular, with slightly concave lateral margins, width ca. 1.4 times length, ca. 1.1 times longer than sixth segment, width of sixth segment ca. 2.3 times length. G1 (fig. 3c-e) slender, tip of G1 reaching beyond suture between thoracic sternites 4 and 5 in situ, with distinct longitudinal groove on ventral outer layer of both distal and subdistal segments; proximal outer part of subdistal segment moderately convex. Distal segment shorter than subdistal segment, gradually bent inwards, weakly compressed dorso-ventrally, subdistally narrowed. Distal segment of G2 (fig. 2f) as long as distal segment of G1, flagellum ribbon-like, length almost as long as narrowed part of basal segment.

Etymology. - The species is named after the type locality, Nanan City, Fujian Province, China. The name is used as a noun in apposition.

Distribution and habitat. - Bottapotamon nanan $\mathrm{n}$. sp. is known only from the type locality (Dongtian County, Nanan City, Fujian Province, China; 420 m a.s.1.). The species was found from under rocks in a branch of the Dongtian River, which has not been mapped.

The topography of Nanan City and surroundings shows a typical "northwest high and southeast low" stepwise gradient from mid- and lower mountains, gradually transiting to a hilly platform, a plain, a slope area known as $\mathrm{Lu}$, and then the beach. This geological structure is part of the "Yan Mountain Structure". The vegetation is the wet, warm subtropical rain forest type of the eastern part of the southeast Dai Yun Mountain in Fujian Province. The climate is classified as the maritime monsoon climate of the southern subtropical region with an average annual temperature of $20.9^{\circ} \mathrm{C}$, ranging from $28.6^{\circ} \mathrm{C}$ in July to $12.1^{\circ} \mathrm{C}$ in January, an annual rainfall of $1600 \mathrm{~mm}$, and a frost-free period of 330 days a year. The Lan 


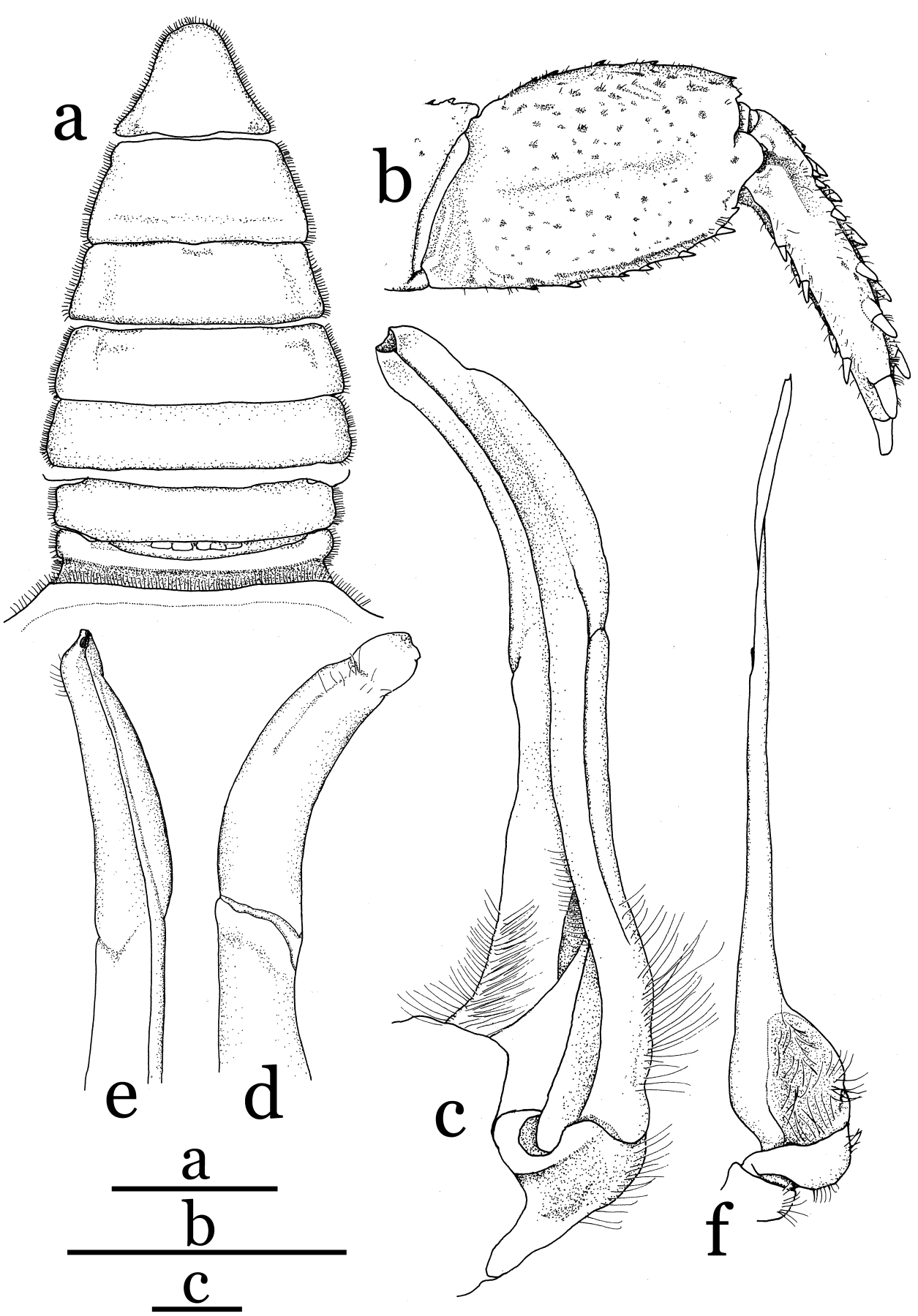

Fig. 2. Bottapotamon nanan $\mathrm{n}$. sp. (holotype male, $22.4 \times 27.2 \mathrm{~mm}$ ); a, abdomen and telson; b, right fourth ambulatory leg; c, left G1, ventral view; d, distal segment of left G1, dorsal view; e, distal segment of left G1, mesial view; f, left G2. Scales, a, b, $5 \mathrm{~mm}$; c, $1 \mathrm{~mm}$. 
River, also known as Dong Tian River, is the main drainage of Nanan City. It is over $30 \mathrm{~km}$ long, and becomes a branch of the Jin River in the suburbs of Nanan City.

Remarks. - Bottapotamon nanan $\mathrm{n}$. sp. is characterized by its relatively long and strongly curved distal segment of the G1, and the relatively stout ambulatory legs. In this regard, the new species is very similar to $B$. yonganense (Cheng, Lin \& Luo, 1993) and B. engelhardti (Bott, 1967). However, B. nanan can easily be differentiated from $B$. yonganense by the shape of its G1. In B. nanan, the distal segment of the G1 is weakly curved inwards, and the distal segment is narrowed subdistally (fig. 2c). In B. yonganense, the distal segment is strongly curving inwards and the distal segment is narrowed only distally (cf. Cheng et al., 1993, fig. 3; Dai, 1999, fig. 219(4)). Bottapotamon nanan can be distinguished from $B$. engelhardti by the weakly incurved distal segment of the G1 (vs. strongly curved in B. engelhardti), and the subdistally narrowed distal segment (vs. distally narrowed distal segment in B. engelhardti) (fig. 2c; Bott, 1967, fig. 3; Türkay \& Dai, 1997, fig. 1(4)).

Bott (1967) originally described B. engelhardti from Foutschau (= Fu Zhou), eastern Fujiang Province, China. Subsequently Türkay \& Dai (1997) and Dai (1999) provided detailed descriptions as well as drawings of the G1 of B. engelhardti, with additional specimens from Shanwu (= Shao Wu) County, western Fujian Province. Interestingly, there are slight differences in the figures of the G1s by Türkay \& Dai (1997) and Dai (1999). The right G1, drawn by Türkay \& Dai (1997, figs. 1, 4), has a relatively narrower subdistal segment and a less prominently curved distal segment. However, the left G1, drawn by Dai (1999, fig. 218(4, 5), has a relatively stouter subterminal segment and a more curved distal segment. Unfortunately, Türkay \& Dai (1997) and Dai (1999) did not mention the locality of the drawn specimens, and Bott's (1967) figure of the type specimen from the eastern region of Fujian Province is not detailed enough to help us resolve this uncertainty. There is, therefore, a need to carry out a close examination of specimens from both the eastern and western regions of Fujian Province to clarify their identities. In any case, the differences between $B$. nanan and B. engelhardti are such that we have no doubt that we are dealing here with a novel species.

The subdistally narrowed terminal segment of the G1 of B. nanan is perhaps similar to that of B. fukiense (Dai, Chen, Song, Fan, Lin \& Zeng, 1979). However, the subdistal region of the distal segment of B. fukiense is constricted and not as narrowed along its distal end (fig. 2c; Dai et al., 1979, fig. 3(3); Türkay \& Dai, 1997, fig. 2(4)). Furthermore, the lateral margin of the proximal part of the subterminal segment is straight and not swollen in B. fukiense (vs. moderately 
swollen in $B$. nanan), and the ambulatory legs are relatively more slender (vs. stouter ambulatory legs in B. nanan) (figs. 1a, 2c; Dai et al., 1979, fig. 3(3); Türkay \& Dai, 1997, fig. 2(4), pl. 1(2)).

\section{ACKNOWLEDGMENTS}

We are grateful to Peter K. L. Ng (National University of Singapore) for supporting this study; Zou Jiexin (Medical College of Nanchang University) Shih Hsi-Te (National Chung Hsing University, Taiwan), and Ng Ngan Kee (National University of Singapore) for their help in our laboratory study and field work. This study was supported by the National Natural Science Foundation of China (NNSFC No. 30660167); Parasite Specimens of China (PSIC No. 2005DKA21104, No. 2005DKA21100); and the National University of Singapore (R-154-000-222-112). The second author was supported by a visiting research fellowship from the Raffles Museum.

\section{REFERENCES}

BotT, R., 1967. Potamiden aus Ost-Asien (Parapotamon De Man, Sinopotamon n. gen., Candidiopotamon n. gen., Geothelphusa Stimpson) (Crustacea, Decapoda). Senckenbergiana biol., 48 (3): 203-216, pls. 7-10.

— - 1968. Potamiden aus Süd-Asien (Crustacea, Decapoda). Senckenbergiana biol., 49 (2): 119-130.

Cheng, Y.-Z., J.-X. LIN \& X.-Q. LuO, 1993. A new species of crab of the genus Malayopotamon (Decapoda: Isolapotamidae). Acta zootaxon. Sinica, 18 (4): 412-416. [In Chinese with English summary.]

Cheng, Y.-Z., W.-C. YAng, Y.-H. Zhong \& L. LI, 2003. A new species of the genus Nanhaipotamon (Decapoda: Potamidae). Journ. Xiamen Univ., (Nat. Sci.) 42 (5): 676-678. [In Chinese with English summary.]

DAI, A. Y., 1999. Fauna sinica (Arthropoda. Crustacea. Malacostraca. Decapoda. Parathelphusidae. Potamidae): 1-501, figs. 1-238, pls. 1-30. (Science Press, Beijing). [In Chinese with English summary.]

DAI, A. Y., G.-X. Chen, Y.-Z. Song, P.-F. FAN, Y.-G. Lin \& Y.-Q. Zeng, 1979. On new species of freshwater crabs harbouring metacercariae of lung flukes. Acta zootaxon. Sinica, 4 (2): 122-131, pl. 1. [In Chinese with English summary.]

MAN, J. G. DE, 1907. On a collection of Crustacea, Decapoda and Stomatopoda, chiefly from the Inland Sea of Japan; with descriptions of new species. Trans. Linn. Soc, London, 9 (11): 387-454, pls. 31-33.

NARUse, T., D. C. J. Yeo \& X.-M. Zhou, 2008. Five new species of freshwater crabs (Crustacea: Decapoda: Brachyura: Potamidae) from China. Zootaxa, 1812: 49-68.

NG, P. K. L., D. Guinot \& P. J. F. Davie, 2008. Systema Brachyurorum, Part I. An annotated checklist of extant brachyuran crabs of the world. Raffles Bull. Zool., (Suppl.) 17: 1-286.

TÜRKAY, M. \& A. Y. DAI, 1997. Review of the Chinese freshwater crabs previously placed in the genus Malayopotamon Bott, 1968 (Crustacea: Decapoda: Brachyura: Potamidae). Raffles Bull. Zool., 45 (2): 189-207. 
Yeo, D. C. J., P. K. L. NG, N. Cumberlidge, C. Magalhães, S. R. Daniels \& M. R. CamPOS, 2008. Global diversity of crabs (Crustacea: Decapoda: Brachyura) living in freshwater. In: E. V. BAlian, C. LÉvêQue, H. SEgers \& K. MARTENS (eds.), Freshwater animal diversity assessment. Hydrobiologia, 575: 275-286.

First received 5 August 2008

Final version accepted 12 August 2008. 